\title{
Ebola, Twitter, and misinformation: a dangerous combination?
}

\author{
Sunday Oluwafemi Oyeyemi clinician ${ }^{1}$, Elia Gabarron research psychologist ${ }^{2}$, Rolf Wynn professor ${ }^{3}$ \\ ${ }^{1}$ Accident and Emergency Department, State Specialist Hospital, Akure, Nigeria; ${ }^{2}$ Norwegian Centre for Integrated Care and Telemedicine, University \\ Hospital of North Norway, Tromsø, Norway; ${ }^{3}$ Department of Clinical Medicine, Arctic University of Norway, Tromsø, Norway
}

The recent Ebola outbreak in west Africa has affected countries deeply in need of foreign aid. ${ }^{1}$ People desperately need correct information on how to prevent and treat Ebola. Despite the poverty, the increasing spread of computers, tablets, and smartphones in the region creates an opportunity for the rapid dissemination of information through the internet and social media, but there is no guarantee that this information is correct. After reports that misinformation spread by text messages led to deaths,${ }^{23}$ we checked the quality of Ebola related information on Twitter.

We used the Twitter search engine to collect all tweets in English with the terms "Ebola" and "prevention" or "cure" from Guinea, Liberia, and Nigeria during 1 to 7 September 2014. We grouped them into medically correct information, medical misinformation, and other (including tweets of a spiritual nature). Most tweets and retweets contained misinformation, and misinformation had a much larger potential reach than correct information (table $\Downarrow$ ).

The most common misinformation was that Ebola might be cured by the plant ewedu or by blood transfusion (unqualified-not just from Ebola survivors). Drinking and washing in salty water were also mentioned. Among these tweets, 248 (44\%) were retweeted at least once; 95 of these contained scientifically correct information $(38.3 \%)$, whereas 146 contained medical misinformation $(58.9 \% ; \mathrm{P}<0.001)$. Two of these tweets- "Take ewedu daily to prevent and cure Ebola LUTH doctor urges Nigerians" and "Herbal healers' claim to cure Ebola false" - were retweeted 23 and 24 times, respectively. While most erroneous tweets were left undisputed, in some cases they were corrected by a Nigerian government agency and this correction spread on Twitter three days later. Public health and government agencies in west Africa should use Twitter to spread correct information and amend misinformation on how to deal with this emergency.

\section{Competing interests: None declared.}

Full response at: www.bmj.com/content/349/bmj.g5975/rr/776571.

Gulland A. Cuts in aid are linked to Ebola crisis, say MPs. BMJ 2014;349:g5975. (2 October.)

2 Wagner M. Phony Ebola cures spread online; 2 Nigerians die from drinking salt water to ward off virus, UN says. New York Daily News 2014. www.nydailynews.com/life-style/ health/phony-ebola-cures-spread-online-article-1.1905855.

3 Nanlong M-T. Nigeria: Ebola-two die after drinking salt water in Jos. Vanguard 2014. http://allafrica.com/stories/201408111640.html. 


\section{Table}

Table 1 | Types of tweets and potential readers $(\mathbf{n})$

Medically correct information Medical misinformation Other (including tweets of a spiritual nature)

\begin{tabular}{lccc}
\hline Tweets (\%) & $203(36)$ & $313(55.5)$ & $48(8.5)$ \\
\hline Potential readers & 5596153 & 15039097 & 48308 \\
\hline Retweets $^{*}$ & 95 & 146 & 7
\end{tabular}

${ }^{*} X^{2}$ test, $P<0.001$ 